\title{
Perfil docente e desenvolvimento de competências em ciências da terra num curso
}

\section{técnico}

\section{Teacher profile and competencies development in earth sciences in a technical}

\section{course}

\author{
Gleise dos Santos*, Jorge Bonito** Celso Dal Ré Carneiro* \\ * Instituto de Geociências/Unicamp, Brasil, **Universidade de Évora, CIDTFF/Universidade de Aveiro, Portugal.
}

\begin{abstract}
Resumo
Dentre as várias disciplinas do Curso de Técnico em Meio Ambiente, do Centro Estadual de Educação Tecnológica Paula Souza, em São Paulo (Brasil), as Práticas de Ciências da Terra lecionam-se no Módulo I. O objetivo deste estudo foi relacionar a formação docente de Práticas de Ciências da Terra com as competências e habilidades definidas em plano de curso. A análise dos resultados permite identificar algumas dissonâncias existentes no modo como se leciona a componente curricular de Práticas de Ciências da Terra, em particular, como se promove, nos alunos, o desenvolvimento das competências exigidas.

Palabras clave: Práticas em ciências da Terra, meio ambiente, perfil docente.
\end{abstract}

\begin{abstract}
Amongst the several you discipline of the Course of Technician in Environment, of the State Center of Technological Education Paula Souza, in São Paulo (Brazil), the Practical ones of Sciences of the Land are lecionam in Module I. The objective of this study was to relate the teaching formation of Practical of Sciences of the Land with the abilities and abilities defined in course plan. The analysis of the results allows to identify some existing dissonâncias in the way as if leciona the curricular component of Practical of Sciences of the Land, in particular, as it is promoted, in the pupils, the development of the demanded abilities.

Keywords: Pratices in Earth Sciences, Environment, Faculty profile
\end{abstract}

\section{Introdução}

No Brasil a educação profissional vem sendo readequada aos novos requisitos do mercado de trabalho. Corrobora para esse avanço a legislação educacional que pressupõe a incorporação de conhecimentos que habilitem jovens para o trabalho a viver de maneira autónoma e em melhores condições de assegurar a sua manutenção ou incorporação no mercado. Neste contexto, o novo profissional técnico deve ser formado com ênfase na aprendizagem de habilidades cognitivas, comunicativas e criativas, desenvolvendo competências comportamentais, tais como trabalho em equipe, autonomia e visão sistémica e, ainda, competências técnicas, como multifuncionalidade, capacidade de aprender e de transferir conhecimento.

O Centro Estadual de Educação Tecnológica Paula Souza (CEETEPS) vem formando profissionais técnicos em diversas áreas, entre elas a ambiental. O curso Técnico em Meio Ambiente, com currículo próprio, capacita o aluno para se tornar um profissional que seja capaz de indentificar, analisar, minimizar e prevenir consequências das intervenções antrópicas no ambiente, dispondo de conhecimento e tecnologias contemporâneas, agindo de forma proativa e ética, contribuindo assim para o desenvolvimento sustentável. O curso está organizado em 3 módulos semestrais, num total de $1500 \mathrm{~h}$ de formação.

O currículo foi desenvolvido ao longo de três eixos principais - Ciências da Terra, Biologia e Química -, o que garante um leque de disciplinas básicas e técnicas capazes de promover nos alunos o desenvolvimento das competências necessárias para sua atuação no mercado de trabalho. Práticas em Ciências da Terra é uma das disciplinas presentes no currículo do curso, representando, por vezes, a base de outras disciplinas técnicas. O conteúdo baseia-se em geografia física, dentro de uma visão sistémica para a abordagem ambiental. O seu conteúdo está estruturado de forma a considerar a dinâmica e a génese do planeta Terra atrelada aos processos antropogénicos. As competências gerais a serem desenvolvidas pela disciplina de Práticas em Ciências da Terra são propostas como: “a) identificar agentes da dinâmica interna responsáveis pela construção e distribuição de paisagens; b) relacionar as características do solo com os diversos fatores de formação, seus tipos e usos correlacionando as suas características físicas, químicas e microbiológicas com sua produtividade; e c) caracterizar as bacias hidrográficas brasileiras identificando e avaliando os elementos que a compõem e os responsáveis pelo ciclo hidrológico" (Centro Estadual de Educação Tecnológica Paula Souza, 2009).

Diante das competências expostas para formação do profissional de técnico em meio ambiente, que cabem à disciplina "Práticas em Ciências da Terra" desenvolver, questiona-se: qual a influência da formação acadêmica 
do professor para se atingir bons resultados no ensino-aprendizagem?

A pesquisa, desenvolvida entre os anos de 2009 e 2010, propôs analisar o ensino de Práticas em Ciências da Terra no ensino técnico em Meio Ambiente, realizando diagnóstico da formação docente e, ainda, avaliando a aceitação e assimilação pelos alunos dessa ciência dinâmica e de integração que, com as demais disciplinas, forma um complexo elo para o conhecimento ambiental.

\section{Método}

O método investigativo desenvolveu-se por processo de pesquisa de natureza mista. Trabalhou-se a análise de questionários aplicados aos docentes de Práticas em Ciências da Terra, bem como com a oportunidade de entrevistá-los, na tentativa de analisar, pelos discursos, metodologias de ensino que identifiquem a qualidade da formação técnica profissional. (Perez Filho \& Bortolozzi, 2000).

A aplicação dos questionários foi realizada on-line, mediante contato preliminar com os diretores de cada unidade escolar que oferecia o curso Técnico em Meio Ambiente, para esclarecimento sobre o assunto e posterior colaboração do mesmo na aplicação do instrumento de avaliação.

O estudo contou com a participação de docentes e alunos de Práticas de Ciências da Terra, integrados em 19 unidades escolares, das 32 que ofereciam o respectivo curso técnico. Foram inquiridos, por questionário, 19 professores e entrevistados, destes, 6 docentes. Foi aplicado, também, um questionário a 286 alunos, com a visita do pesquisador às escolas participantes.

O questionário aplicado aos alunos contemplou 50 alunos que cursavam o primeiro módulo do curso, 200 alunos que cursavam o segundo módulo e 36 alunos que cursavam o terceiro módulo final. Aos alunos do segundo módulo coube a maior parte da pesquisa, pois os mesmos já haviam cursado a disciplina de Práticas em Ciências da Terra. Aos alunos de terceiro e primeiro módulos, coube uma menor representatividade, pois os mesmos, ou já podiam não se lembrar de dados mais específicos em relação ao que se questionava, ou por sua vez, podem revelar o quanto e como a disciplina estaria em desenvolvimento, respectivamente.

\section{Resultados}

A tabulação dos dados quantitativos, que teve por objetivo levantar características da população amostral dos professores pesquisados, revela que, dos 19 questionários coletados, 15 docentes são homens. Relativamente à formação acadêmica desses docentes nota-se grande variedade de profissionais, uma vez que o Catálogo de Requisito de Titulação para Docência, criado pelo próprio CEETEPS, estabelece para cada componente curricular a correspondente titulação dos docentes habilitados a ministrar as disciplinas dos cursos técnicos.

A partir dessa informação, puderam-se mapear as formações específicas de cada docente (Fig. 1), sendo que a maioria deles $(f=10)$ é formada em Geografia. $\mathrm{Na}$ área das engenharias, aparece uma diversidade entre Engenharia Agronómica, Engenharia Civil, Engenharia Florestal, Arquitetura/Urbanismo; outras formações académicas também são registradas, como Ciências Biológicas e Química.

\begin{tabular}{|c|c|}
\hline Geografia & Engenharia Agronômica \\
\hline Ciências Biológicas & Engenharia Florestal \\
\hline —Química & Arquitetura e Urbanismo \\
\hline
\end{tabular}

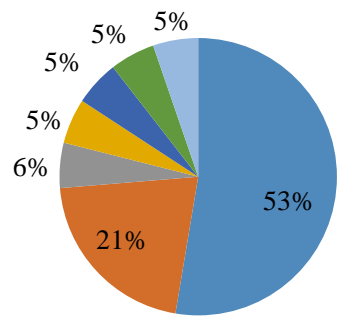

Figura 1. Quadro de formações específicas dos docentes pesquisados

Muitos docentes deram continuidade aos estudos por meio de cursos de especialização $(f=10)$ ou mesmo mestrado $(f=6)$, sendo que a maioria concentrou seus estudos na área de ensino, de Geografia, de Geociências, de Engenharia Agronómica, Educação Ambiental, e Metodologia e Didática do Ensino Superior. Outros estudos realizados pelos docentes correspondem às áreas de conservação do solo, mineração, engenharia ambiental, ecologia urbana, gestão e estratégias de marketing. Esse quadro diversificado constitui uma base que deve ser levada em conta ao se discutir a questão pedagógica em relação à disciplina de Práticas em Ciências da Terra.

Para a investigação das práticas pedagógicas, apresentaram-se aos docentes onze metodologias de ensino por meio de afirmações, as quais eles deveriam selecionar aquelas de utilização mais frequente, segundo as categorias descritas na tabela 1.

As afirmações 6-10 representam metodologias de interação entre docentes e alunos, que caracterizam professores mais ativos em relação ao processo de ensino e aprendizagem, enquanto as afirmações 1-5 e 11 representam metodologias mais passivas e conservadoras, nas quais o professor é mero instrumento de transmissão de conhecimento e não de construção de saberes (Santos , 2011).

Analisando as metodologias indicadas, encontra-se uma relação interessante entre as afirmações 1, 4 e 5, pois a maioria dos professores assinalou a alternativa "às vezes" e ainda utiliza sempre recursos áudio-visuais para manter práticas conservadoras, o que é confirmado pela afirmação 2. Por outro lado, os mesmos docentes assinalaram como "sempre" as afirmações 7-9, reforçando a contradição de que a maioria dos professores nunca apresenta "a matéria como um corpo de conhecimento acabado" e apresenta "várias visões existentes sobre um assunto". 
A utilização de livros ou textos foi sugerida como prática em outra questão. Dez docentes dizem que não adotam essa prática; oito adotam livros ou textos, os quais são fotocopiados pelos alunos para estudarem em casa; e apenas um professor adota uma única apostila, elaborada por ele próprio, o que conflita com os comentários que teceram sobre o curso técnico em meio ambiente, dos quais sete deles deixaram a questão em branco, ou sem resposta. Isso indica que ou não responderam por vontade própria, ou não souberam responder por que não conhecem o curso e a disciplina em que lecionam. As respostas evidenciam uma mescla de práticas pedagógicas que podem ser influenciadas pela formação académica, pela falta de conhecimento didático-pedagógico do docente, e ainda pelas condições estruturais da escola e do curso.

Tabela 1.

Práticas pedagógicas possíveis adotadas pelos docentes

\begin{tabular}{|c|c|c|c|}
\hline Afirmações & Sempre & Às vezes & Nunca \\
\hline $\begin{array}{l}\text { 1- Costumo dar a maior } \\
\text { parte de minhas aulas de } \\
\text { forma expositiva }\end{array}$ & 8 & 11 & 0 \\
\hline $\begin{array}{l}\text { 2- Valorizo conhecimento } \\
\text { de detalhe ou informações } \\
\text { específicas sobre o } \\
\text { conteúdo da disciplina }\end{array}$ & 16 & 3 & 0 \\
\hline $\begin{array}{l}\text { 3- Apresento a matéria } \\
\text { como um corpo de } \\
\text { conhecimento acabado }\end{array}$ & 2 & 2 & 13 \\
\hline $\begin{array}{l}\text { 4- Estimulo a memorização } \\
\text { do conhecimento }\end{array}$ & 5 & 11 & 3 \\
\hline 5- Utilizo somente apostilas & 1 & 13 & 5 \\
\hline $\begin{array}{l}\text { 6- Incentivo os alunos a } \\
\text { construírem maquetes, } \\
\text { mapas, modelos, etc }\end{array}$ & 4 & 14 & 1 \\
\hline $\begin{array}{l}\text { 7- Organizo e oriento } \\
\text { trabalhos e discussões em } \\
\text { grupo }\end{array}$ & 11 & 7 & 1 \\
\hline $\begin{array}{l}\text { 8- Procuro relacionar os } \\
\text { temas do meu programa } \\
\text { com os fatos da realidade }\end{array}$ & 18 & 1 & 0 \\
\hline $\begin{array}{l}\text { 9- Apresento as várias } \\
\text { visões existentes sobre um } \\
\text { assunto, em minhas } \\
\text { exposições }\end{array}$ & 17 & 2 & 0 \\
\hline $\begin{array}{l}\text { 10- Promovo trabalhos de } \\
\text { campo, com roteiros de } \\
\text { pesquisa }\end{array}$ & 7 & 11 & 1 \\
\hline $\begin{array}{l}\text { 11- Utilizo materiais } \\
\text { áudio-visuais (mapas, } \\
\text { filmes, slides etc) }\end{array}$ & 11 & 8 & 0 \\
\hline
\end{tabular}

Recordando que $63 \%$ dos inquiridos cursaram licenciatura nas áreas de Ciências Humanas (geógrafos), Biologia e Química, com a finalidade de atuarem na área educacional, devem ter cursado disciplinas como psicologia da educação, didática, metodologias e práticas educacionais. Os demais docentes inquiridos, $37 \%$, são engenheiros e arquitetos que, pela própria formação, não receberam qualquer conhecimento ou habilidade para atuar na área educacional.

Observa-se, portanto, que a deficiência docente, tanto em conhecimento, como em práticas pedagógicas, origina-se nas próprias formações acadêmicas, que são aceitas pelo Catálogo de Requisitos de Titulação para Docência, do CEETEPS, interferindo diretamente na qualidade do ensino oferecido aos alunos.

As informações reveladas pelos alunos sobre o conhecimento em relação ao professor traduzem as práticas pedagógicas que se utiliza em aulas para que se desenvolvam as competências necessárias requeridas pela disciplina. A pergunta que revela as práticas pedagógicas adotadas pelos professores explicitam sete diferentes atividades (Fig. 2). Considera-se que cada um dos alunos poderia assinalar mais de uma opção. Assim, o número de respostas apontadas na figura 2 não coincide eom o número de alunos questionados. Assim, optou-se ão pela apresentação dos dados em porcentagem, de acordo ei com as sete práticas pedagógicas referenciadas. A utilização recursos áudio-visuais para ilustrar assuntos

0 abordados em Práticas em Ciências da Terra aparece com a maior frequência em relação às demais práticas sugeridas como resposta.

0

\section{Práticas Pedagógicas exercidas pelos Docentes}

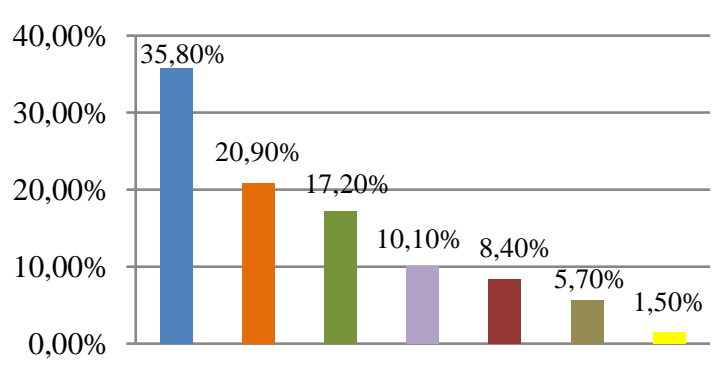

- Aulas expositivas com auxílio de slides, filmes ou outras ferramentas

- Aulas práticas

- Visitas de campo

Aulas em laboratório

- Somente aulas expositivas

Figura 2. Práticas pedagógicas utilizadas pelos docentes

As aulas práticas são realizadas dentro da estrutura oferecida pelas escolas. As visitas a campo buscam exemplos naturais na paisagem para ilustrar e melhorar as aulas expositivas, primando pela interação dos alunos com os elementos naturais, satisfazendo a 
contextualização do processo de ensino e aprendizagem. As aulas em laboratório são em número reduzido devido à falta destes ou a insuficiência de equipamentos e materiais para análises nas unidades escolares, como citados pelos docentes. As demais práticas pedagógicas, segundo os alunos inquiridos, são bem menos praticadas. Entretanto, o número expressivo de alunos que apontam o trabalho docente somente com aulas expositivas leva-nos a reflexão sobre a qualidade dessas aulas e se atinge o grau de competências e habilidade exigidas pela disciplina.

Analisando todos esses dados, relembrando as competências exigidas pela disciplina e pelo curso, e a formação académica dos docentes, deve-se avaliar como os alunos desenvolvem tais competências, e se realmente chegam a este propósito.

\section{Discussão}

O ponto de partida desta discussão é a busca de respostas satisfatórias à questão que levou a este processo de investigação: qual é o perfil do profissional qualificado para a e lecionar Práticas em Ciências da Terra em cursos técnicos em Meio Ambiente e desenvolver nos alunos as competências e habilidades exigidas pela disciplina e pelo curso?

A má formação académica resulta em deficiências conceituais dos professores formados, gerando um processo de ensino-aprendizagem deficiente quanto aos conteúdos relacionados às ciências da terra.

Para tanto, além da pesquisa direta com os docentes, realizou-se uma pesquisa paralela em relação aos cursos de formação acadêmica dos profissionais envolvidos, ou seja, qual a carga horária de disciplinas, diretamente ligadas ás Ciências da Terra, disponibilizada nos cursos acadêmicos dos profissionais habilitados pelo CEETEPS para ministrarem a disciplina em questão. Foram analisados 26 cursos referentes às ciências da terra, em 31 unidades de formação acadêmica superior.

Dois terços das universidades que formam profissionais habilitados pelo CEETEPS apresentam a carga horária de disciplinas específicas (geologia geral, evolução e dinâmica interna da Terra, geologia dinâmica e estratigrafia, geologia ambiental, geologia aplicada ao solo, fundamentos das ciências do solo, pedologia, geoquímica, geologia e geomorfologia, geologia de engenharia, mineralogia, águas subterrâneas, movimentos de terra, hidrogeologia, ciência do solo, geomorfologia estrutural, geologia sedimentar, paleontologia e geofísica) até 3,0 \% do total da carga horária do curso considerado. Apenas os cursos de Engenharia de Minas, Geociências e Educação Ambiental, Geografia e Geologia possuem carga horária maior ou igual a $10 \%$ do total de disciplinas específicas em Ciências da Terra.

Portanto, a debilidade docente, tanto em conhecimento, como em práticas pedagógicas, origina-se nas próprias formações acadêmicas aceitas pelo CEETEPS. Tal procedimento interfere diretamente na qualidade do ensino oferecido aos alunos.

A transposição didática de conteúdos das ciências da terra para o ensino técnico profissional pode estimular o exercício de habilidades específicas de interpretação da realidade por meio do pensamento indutivo, que privilegia a formulação de hipóteses causais múltiplas e permite que o aluno considere diferentes pontos de vista (Barbosa, 2008, citado por Santos, 2011).

Entretanto, como um professor, com deficiências em sua formação académica, pode provocar o desenvolvimento de competências necessárias a formação técnica profissional?

A diferença entre um professor e um professor reflexivo vai além de suas ações cotidianas; essa diferença pode ser compreendida pela ação, pela sensibilidade intuitiva, pela habilidade em provocar sonhos e a capacidade de usufruir a condição de amante movido pela vocação e pelo compromisso social com uma práxis crítica e criativa (Leal, 2006, citado por Santos, 2011)

De sorte, as competências somente serão atingidas quando forem contemplados no processo de aprendizagem os quatro pilares da educação necessários ao desenvolvimento do ser humano: a) aprender a conhecer; b) aprender a fazer; c) aprender a conviver; d) aprender a ser (UNESCO, 1998, citado por Rodrigues, 2009).

Tais aprendizagens fazem parte, ao mesmo tempo, da aquisição de conhecimento formal e do processo de formação continuada do indivíduo. De acordo com esses eixos a educação técnica deve priorizar a formação de um profissional capaz de mobilizar, articular e colocar em ação conhecimentos, habilidades, atitudes e valores. A formação deverá estar voltada para o desenvolvimento, a aplicação, a administração e a difusão de tecnologias. (Santos e Carneiro, 2009)

A análise dos resultados ainda permitiu identificar algumas dissonâncias existentes no proceso, destacam-se: a) a formação dos docentes é limitante para a abordagem de todas as bases tecnológicas de Práticas de Ciências da Terra; b) a carga horária é considerada insuficiente para se desenvolverem as competências e habilidades definidas no plano de curso; c) as práticas pedagógicas estão indexadas, de modo generalizado, a componentes de natureza teórica, minimalizando a existencia de atividades de campo e de laboratório e de outras técnicas didáticas indicadas para o ensino das Ciências da Terra.

Considerando-se a especificidade do conteúdo a ser abordado e a formação académica dos profissionais habilitados, conclui-se que o profissional mais qualificado para a função docente desta disciplina deve:

- possuir formação académica na qual os temas geológicos tenham sido abordados em carga horária e profundidade suficientes para que ele conheça minimamente os temas presentes na grade curricular do curso técnico;

- possuir formação pedagógica, na qual estejam contempladas disciplinas específicas para formação de professores;

- manter-se atualizado sobre novas metodologias de ensino e buscar aprimoramento em práticas pedagógicas mais eficientes; 
- ser um professor reflexivo, comprometido com sua profissão, capaz de levantar dúvidas sobre seu próprio trabalho, entender os contextos nos quais trabalha (escola e sala de aula) e, ao interpretá-los, adaptar sua atuação a eles.

O professor da disciplina deve ser capaz de desenvolver no aluno as competências necessárias para que o futuro profissional atue de forma eficiente e eficaz no mercado de trabalho. Esse ofício exige estabelecer conexões entre o conhecimento dos processos naturais e da história da Terra com o trabalho profissional em nível técnico.

Também a política de expansão quantitativa da educação profissional se define como uma estratégia de multiplicação de oportunidades em lugar da qualificação das oportunidades abertas à sociedade. Assim, os problemas com professores não se restringe à formação acadêmica de cada um, nem tampouco às práticas pedagógicas utilizadas.

Tal situação polémica colide frontalmente com as exigências do professor moderno, devendo as práticas, individuais e coletivas, demonstrarem que para ser professor é indispensável o zelo, o cuidado, a competência humana, o conhecimento tácito, a reflexão sobre as práticas. $\mathrm{O}$ papel do professor hoje deve ser de agente transformador da informação em conhecimento, das teorias e hipóteses em raciocínios, dos fatos isolados em correlações entre fatos, do conteúdo fragmentado em uma visão integrada dos processos envolvidos nos sistemas.

O quadro revelado neste estudo, por meio dos testemunhos dos sujeitos envolvidos, dá conta da importância da adequação do perfil de formação profissional do docente a esta componente curricular. Os resultados apontam para que a carga horária de Práticas de Ciências da Terra seja ampliada; que a política de contratação de docentes do CEETEPS assente em pressupostos de curricula vitae que sejam ajustados às competências e habilidades definidas para as Práticas de Ciências da Terra, restringindo a lista de profissionais habilitados; capacitar/reciclar professores na ativa; alterar critérios e sistema de seleção para docentes das Escolas Técnicas, além de implementar política de valorização do corpo docente (Carneiro e Santos, 2012). Parece ser necessário investir em equipamentos e materiais, principalmente os utilizados em aulas práticas/campo, e também e proceder a uma reanálise do plano de curso em relação a conteúdos e tempo destinados às Práticas em Ciências da Terra e demais disciplinas.

\section{Referências}

Barbosa, R. (2008). O Projeto Geo-Escola como incentivo ao ensino de geociências na educação básica, SP, a partir de experiências realizadas em Campinas. (Dout., qualif.). Universidade Estadual de Campinas. Brasil.

Leal, R. (2006). Professor: saberes e fazeres para além do pedagógico. Revista Iberoamericana de Educação, 37(4),1-5. Disponível em: http://www.rieoei.org/1120.htm.
Perez Filho, A. \& Bortolozzi, A. (2000). Diagnóstico da Educação Ambiental no Ensino de Geografia. Cadernos de Pesquisa, 109, 145-171.

Rodrigues, Z. B. (s.d.) Os quatro pilares de uma educação para o século XXI e suas implicações na prática pedagógica. Disponível em: http://www.educacional.com.br/articulistas/outrosEdu cacao_artigo.asp? artigo=artigo0056.

Carneiro, C. D. R. \& Santos, G. R. B. (2012). Ensino de geociências na formação profissional em meio ambiente no estado de São Paulo. Revista Brasileira de Geociências, 42(Suppl 1), 84-95, Disponível em: http://ppegeo.igc.usp.br/index.php/rbg/article/view/80 02

Centro Estadual de Educação Tecnológica Paula Souza. (2009). Plano de Curso Técnico em Meio Ambiente. N. ${ }^{\circ}$ 19. São Paulo: Centro Paula Souza.

Santos, G., \& Carneiro, C. (2009). Aspectos didático-pedagógicos do ensino de Geociências para cursos técnicos em Meio Ambiente. In: Simpósio de Pesquisa em Ensino e História de Ciências da Terra, 2, e Simpósio Nacional sobre Ensino de Geologia no Brasil (pp. 561-570). São Paulo: IGc-USP / IG-Unicamp.

Santos, G. (2011). A disciplina Geociências na formação de técnicos ambientais: prospecção de práticas pedagógicas. (Dissertação de mestrado não publicada). Universidade Estadual de Campinas, Brasil. 